\title{
Функциональная организация архитектурного благоустройства территорий сельских приходских храмов
}

\author{
Роман Другомилов ${ }^{1}$, Юрий Мажайскийํ, Наталья Осина ${ }^{3}$
}

\section{АННОТАЦИЯ:}

В статье представлены предложения по функциональному зонированию архитектурного благоустройства территорий храмов с разделением на две основные зоны: общественную и служебную, которые, в свою очередь, предлагается разбивать на более компактные подзоны. Также предложен конкретный комплект элементов архитектурного благоустройства для наполнения каждой функциональной зоны и подзоны, описаны особенности организации мест исторических захоронений близ храмов и благоустройства культовых мест, расположенных на территориях бывших дворянских усадеб.

\section{КЛЮЧЕВЫЕ СЛОВА:}

архитектурное благоустройство территорий; храм; функциональное зонировани

\section{1. Введение}

Храм в сельской местности с давних времен традиционно имел особое значение для местных жителей. Для него выбиралось лучшее в градостроительном отношении местоположение, храмы, находясь на возвышенности, занимали главенствующее место в системе вертикальных доминант сельских поселений. Храм и территория вокруг него всегда были местом неспешных раздумий, переосмысления отдельных поступков и всей жизни, местом, где для людей открывались невидимые сакральные врата, связывающие наш мир и неведомый, божественный, потусторонний. Кроме того, это было место, в котором в воскресные и праздничные дни собирались сельские жители, в котором особое значение придавалось не только совершаемым церковным обрядам, но и архитектурным формам сооружений: высокие, стремящиеся в небеса колокольни, величественные купола, символические ворота-брамы при входе на территорию храма и др. Немаловажной составляющей архитектурно среды территорий у храмов является и их благоустройство.

\section{2. Современное состояние территорий сельских приходских храмов}

В странах постсоветского пространства в связи с длительным периодом главенствующего атеизма в советское время и уменьшением численности населения в сельской

\footnotetext{
1 Белорусская государственная сельскохозяйственная академия, кафедра сельского строительства и обустройства территорий, ул. Мичурина, 5, 213410, г. Горки, Могилевская обл., Беларусь, эл. почта: roman_drug@mail.ru, orcid id: 0000-0002-0577-6882

2 Белорусская государственная сельскохозяйственная академия, кафедра гидротехнических сооружений и водоснабжения, ул. Мичурина, 5, 213410, г. Горки, Могилевская обл., Беларусь, эл. почта: director@mntc.pro, orcid id: 0000-0002-0743-8289

3 Рязанский институт (филиал) Московского Политехнического университета, ул. Право-Лыбедская, 26/53, 390000, г. Рязань, Россия, эл. почта: ona_apx@mail.ru, orcid id: 0000-0003-1299-9141
} 
местности многие сельские храмы прекратили свое фактическое существование, нередко достигнув руинированного состояния (в Беларуси к таким храмам относятся костел св. Николая XVIII в. в д. Княжицы Могилевского района (рис. 1), костел Вознесения Девы Марии конца XVIII в. в д. Дуброво Молодечненского района, Троицкая церковь середины XIX в. в д. Самотевичи Костюковичского района, церковь св. Ильи начала XX в. в д. Высокое Оршанского района и многие другие) [1-9]. Другие, уже после распада СССР, не имея значительных финансовых поступлений, так и не могут в полной мере восстановиться, включая и конструктивные элементы и благоустройство территорий, прилегающих к храмам. Отрадно отметить, что в последние 30 лет начинают постепенно возрождаться исторические святыни, строятся новые храмы. В то же время, не имея значительных финансовых поступлений, восстановление, реконструкция и строительство храмов идет невысокими темпами, в том числе слабо развивается и архитектурное благоустройство прихрамовых территорий. Это заметно не только по храмам, возведенным в досоветское время (среди которых, впрочем, имеются и хорошие примеры благоустройства например, территория, прилегающая к Троицкому костелу начала XX в. в д. Гервяты Островецкого района, с разветвленной сетью пешеходных дорожек, ограждением, скамьями для отдыха, скульптурой, богатым озеленением, автостоянкой и др.), но и, в особенности, по построенным в последние годы новым приходским сельским храмам, которые пользуются меньшим вниманием со стороны туристов, средств массовой информации, исследователей и ученых. Так, благоустройство территории вокруг церкви в честь иконы Божьей Матери «Семистрельная» в д. Ленино Горецкого района ограничивается лишь озеленением, пешеходной дорожкой, ведущей ко входу в храм, организованным из скамей местом отдыха, деревянным крестом и ограждением по границам участка (рис. 2). На территории Воскресенской церкви в д. Букча Лельчицкого района имеются аналогичные предыдущей церкви элементы благоустройства кроме организованного места отдыха, однако в дополнение к ограждению предусмотрены металлические ворота на входе на территорию храма. На территории церкви св. Пантелеймона в д. Бакшты Ивьевского района перед входом в храм предусмотрена небольшая пешеходная площадь, скамьи, территория огорожена, вход организован в виде тройных арочных каменных ворот-брам с металлическими створками (подобное решение благоустройства также можно увидеть на территории Благовещенской церкви в д. Большие Мотыкалы Брестского района, а решение ворот - на входе на территорию протестантской церкви в д. Волок Узденского района и др.). На территории Петропавловской церкви в д. Овсянка Горецкого района предусмотрено только место отдыха со скамьями и столиком, отсутствуют, в свою очередь, все остальные элементы, в том числе ограждение и даже пешеходная дорожка для подхода к храму. Схожая ситуация на территории церкви св. Елисея Лавришевского в д. Минойты Лидского района и др. Незначительно отличается ситуацию и на территориях небольших малоизвестных исторических храмов, где совокупность элементов благоустройства, зачастую включает в себя лишь ограждения, ворота, пешеходные дорожки, колокольни, места отдыха, кресты, часовни, озеленение (а в ряде случаев отдельные из перечисленных элементов могут и отсутствовать): Покровская церковь середины XIX в. в д. Кищицы Дрибинского района (рис. 2), Церковь Рождества Богородицы середины XIX в. в д. Валувичи Дрогичинского района, Костел Девы Марии середины XIX в. в д. Холхлово Молодечненского района, Успенская церковь конца XIX в. в д. Сухари Могилевского района (рис. 2), Покровская церковь начала XX в. в д. Осиногородок Поставского района, костел Рождества Девы Марии начала XX в. в д. Вязынь и костел Сердца Иисуса начала XX в. в д. Илья Вилейского района и многие другие [2-11].

Одна из причин такого положения дел уже называлась выше - финансирование; вторая - отсутствие достаточной нормативной базы. Не смотря на то, что в последние годы в определенной степени развивается научно-обоснованная сфера проектирования религиозных зданий и сооружений (в Беларуси с 2008 г. действует ТКП 45-3.02-83-2007 (02250) «Культовые здания и сооружения. Здания, сооружения и комплексы православных храмов. Правила проектирования» [12], в России - с 2018 г. - СП 391.1325800.2017 
«Свод правил. Храмы православные. Правила проектирования» [13], практически идентичные друг другу в вопросах благоустройства территории храмов), все же нормативная документация содержит еще не полный перечень требований и рекомендаций, что вызывает определенные проблемы у проектировщиков, занимающихся разработкой проектно-сметной документации по религиозным зданиям и сооружениям. К тому же, в действующих нормативах прописаны определенные требования и рекомендации по благоустройству территории только православных храмов и не рассматриваются храмы других конфессий. Это приводит к тому, что архитекторам-проектировщикам при разработке проектной документации, например, по католическим храмам приходится ориентироваться на общие нормы проектирования общественных зданий в связи с отсутствием других нормативных требований к данному типу объектов. Также в последние годы появляются и научные работы посвященные архитектурным решениям храмов и принципов их проектирования, однако основной акцент в них делается на архитектурно-планировочные решения самих храмов, архитектурную композицию застройки участка, на которой расположен храм, и его озеленению, и практически не уделяется внимание функциональной организации благоустройства прихрамовой территории [11, 14-17]. В настоящей же статье приводятся предложения и рекомендации по организации архитектурного благоустройства территорий храмов, которые могут быть применены как для православных храмов, так и для храмов других религий и вероисповеданий (конфессий) с учетом определенных особенностей.

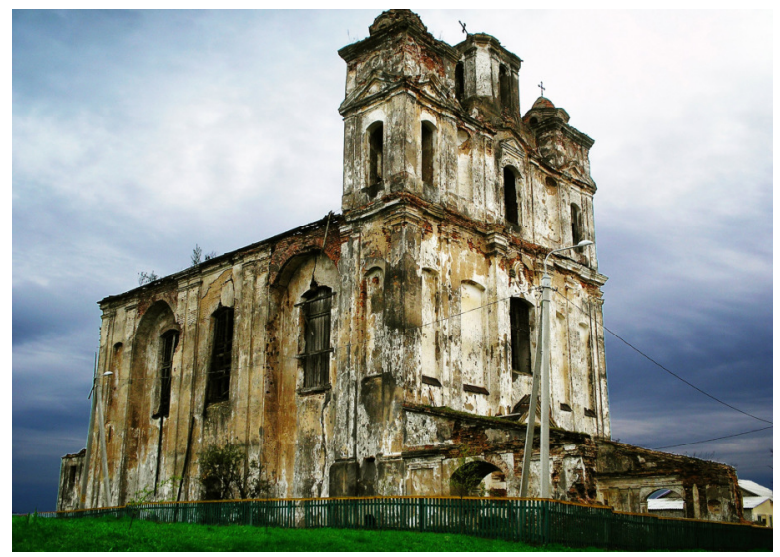

Рис. 1. Костел св. Николая XVIII в. в д. Княжицы Могилевского района (Беларусь)
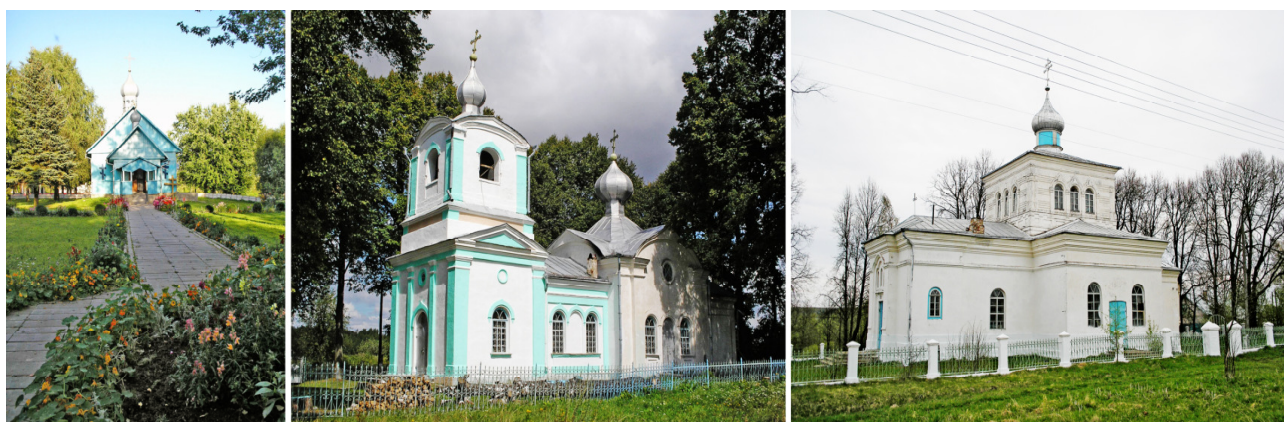

Рис. 2. Примеры организации прихрамовых территорий (слева направо: церковь в честь иконы Божьей Матери «Семистрельная» в д. Ленино Горецкого района, Беларусь; Покровская церковь середины XIX в. в д. Кищицы Дрибинского района, Беларусь; Успенская церковь конца XIX в. в д. Сухари Могилевского района, Беларусь) 


\section{3. Предложения по функциональной организации архитектурного благоустройства территорий сельских приходских храмов}

Для качественной организации территории, прилегающей к храму, ее предлагается разделить на функциональные зоны архитектурного благоустройства [18]. Основных зон две: общественная и служебная. Общественная зона предназначена для пользования преимущественно посетителями, прихожанами, служебная - преимущественно для использования священнослужителями, церковнослужителями, работниками коммунальных служб и др. Эти две зоны также логично разделить на более мелкие подзоны, функциональное назначение которых более детально определяет насыщение их необходимыми элементами архитектурного благоустройства. Примерное расположение зон и подзон показано на рисунке 3. Следует отметить, что, в реальности зоны и подзоны могут не иметь четких границ, а в некоторых случаях могут дополнять друг друга или частично совмещаться.

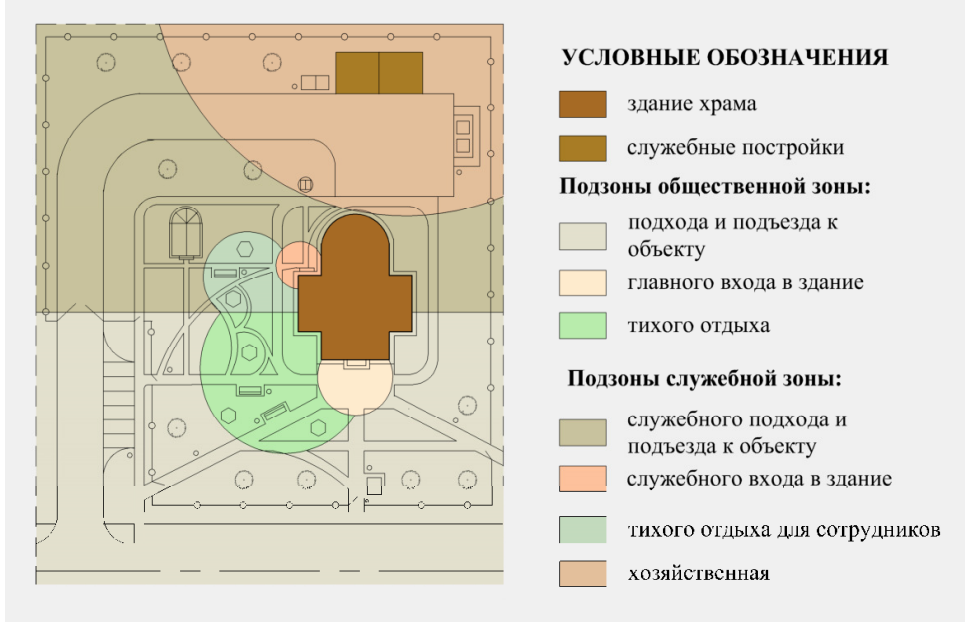

Рис. 3. Схема функционального зонирования архитектурного благоустройства территории храма

В общественной зоне территории храма предлагается выделять следующие подзоны: подзона подхода и подъезда к объекту (зданию храма), подзона главного входа в здание, подзона тихого отдыха. Подзона подхода и подъезда к объекту обеспечивает связь территории храма с остальными территориями населенного пункта. Здесь необходимо размещать автостоянку для посетителей (с твердым покрытием), возможно расположение в этой подзоне церковного киоска, колокольни, мемориальных композиций, скульптуры, креста и других элементов. Территория храма должна быть огорожена. Ограждение может быть решетчатым и выполнено из любых материалов, высота - около 0,8...1,5 м. Неотъемлемым элементом зоны подхода и подъезда к объекту являются створчатые ворота и калитки. Особый эффект имеют проходы на территорию, ограниченные не только с боков, но и сверху - в виде арки или горизонтальной двускатной крышечки. Такое архитектурное решение (брама) создает символический образ портала для перехода из мирского бытия на святую землю. Возможно совмещение отдельно стоящей колокольни с входом на территорию храма в виде брамы-колокольни, в которой на верхнем ярусе расположены колокола, а на нижнем - сквозной проход. Возле входа на территорию и церковных киосков также возможно размещение урн для твердых бытовых отходов (предпочтительно с боковой загрузкой или навесом), а на конструкциях врат и калиток - информационные и предупредительные таблички. Подзона главного входа в здание обеспечивается связь территории храма с внутренним его пространством. Здесь 
рекомендуется устройство разгрузочной пешеходной площади перед входом в храм, наличие лестниц и пандусов с перилами для обеспечения входа в здание любым категориям населения, наличие информационных табличек (с названием храма, историческими сведениями, графиками богослужений, другой важной информацией). Подзона тихого отдыха устраивается для обеспечения возможности прихожанам и посетителям восстановить силы (в сельской местности много пожилых прихожан), тихо пообщаться с другими посетителями, либо в одиночестве поразмыслить о мирском бытие, не торопливо прочувствовать божественное окружение. В этой подзоне рекомендуется размещать скамьи, возможно размещение декоративной скульптуры, организованных родников.

В служебной зоне предлагается следующий перечень подзон: подзона служебного подхода и подъезда к объекту, подзона служебного входа в здание, подзона тихого отдыха для сотрудников храма (может отсутствовать), хозяйственная подзона. Подзона служебного подхода и подъезда к объекту необходима для беспрепятственного доступа к храму и сопутствующим сооружениям священнослужителей, церковнослужителей и работников коммунальных служб без пересечения основных направлений транспортных и пешеходных коммуникационных связей, используемых посетителями и прихожанами. Здесь необходимо устройство хозяйственного проезда с асфальтобетонным покрытием, продолжение ограждения территории храма с устройством калиток и при необходимости ворот для проезда транспорта. Также в этой подзоне возможно размещение мемориалов, отдельных захоронений, небольших часовен и капличек (например, мемориальных) для проведения нерегулярных обрядов. Подзона служебного входа в здание предназначена для непосредственного входа священно- и церковнослужителей в храм. В этой подзоне необходим минимальный состав элементов благоустройства - лестница и пандус с ограждениями (перилами) для входа в храм. Хозяйственная подзона представляет собой часть территории, обеспечивающая возможность обособленного проведения хозяйственных, служебных и санитарно-гигиенических мероприятий и операций. Здесь необходимо размещать погрузочно-разгрузочную площадку с асфальтобетонным покрытием, площадки мусоросборников с соответствующим оборудованием, возможно размещение колодца или водоразборной колонки, а также уличной уборной для посетителей, прихожан и сотрудников. Расположение этой зоны и отдельных ее элементов должно учитывать действующие санитарные нормы. Также в некоторых случаях на территории храма может быть предусмотрена подзона тихого отдыха для сотрудников (при большом их штате). Основным элементов благоустройства этой зоны является уличная мебель (скамьи, столики) и, возможно, декоративная скульптура. Кроме того, при необходимости может быть предусмотрена подзона церковного сада и огорода - для выращивания цветов для проведения служб и сельскохозяйственных культур для организации трапез паломников или малоимущих.

Кроме указанных элементов архитектурного благоустройства для всех зон и подзон необходимо устройство элементов уличного освещения. Для общественной зоны - рационально применять парковые светильники и настенные осветительные приборы в подзоне главного входа в здание, для служебной зоны - также и фонарные столбы. Для всех зон и подзон обязательными являются пешеходные дорожки для обеспечения связи между различными элементами, расположенными на территории, зонами, подзонами, входами в здания и на территорию храмов, а также для проведения необходимых обрядов (например, крестный ход). Покрытие пешеходных дорожек следует предусматривать твердое, предпочтительно из мелкоштучной плитки тротуарной или асфальтобетона. Также на всей территории храма в зависимости от рельефа предусматриваются лестницы и пандусы на пешеходных путях, которые обязательно необходимо оборудовать периллами, а также изделия и устройства для растений (вазы-цветочницы, цветники, жардиньерки и др.), декоративные каменные выкладки и др.

Расположение, конфигурация функциональных зон и подзон, элементов архитектурного благоустройства, их количество и отдельные параметры определяются в зависимости от вместительности храма, реальных условий территории храма (рельеф, расположение 
относительно других общественных, жилых и прочих объектов и территорий, улиц, дорог, проездов), принятой архитектурно-художественной концепции и др. Кроме того, проектирование архитектурного благоустройства территорий храмов должно учитывать требования соответствующих действующих нормативных документов.

\section{4. Особенности организации мест исторических захоронений близ храмов и благоустройства храмов, расположенных на территориях бывших дворянских усадеб}

Важным аспектом в современном проектировании или реконструкции территории сельских храмов является решение проблемы организации мест исторических захоронений. Особую роль в организации территории сельских храмов в дореволюционное время занимало кладбище и места захоронения священнослужителей и почетных граждан. В планировочной структуре сельского храма отдельным блоком выступало кладбище с организацией некрополей богатых прихожан, а особое внимание в православии уделялось захоронениям вблизи церкви - чем ближе к алтарной части храма, тем более значимый вклад в мирской жизни внес усопший. Захоронения вблизи церкви отмечены надгробиями с оригинальными композиционными решениями и их семантический смысл отражается в восприятии культового сооружения. В зависимости от прихода, значимости и функции сельской церкви в дореволюционное время эта важная миссия нашла отражение в планировочной структуре и являлась одним из главных блоков культовой территории. Немало сельских культовых сооружений являлись кладбищенскими по функции изначально, поэтому этот вопрос затрагивает разные конфессии. Более того, организация мест для захоронений исторически включает не только территорию кладбища, но и некрополи, мавзолеи, склепы, а также поминальные часовни и т.д. Выстраивается целая планировочная структура с пространственными и смысловыми доминантами и эта структура существует в настоящее время на территории исторических сельских храмов.

Свои особенности имеет и благоустройство территории храмов, расположенных на территориях исторических дворянских усадеб. Важную роль в организации храмовой территории здесь играли заказчики строительства храма. Именно период расцвета дворянской усадьбы, на периферийных парковых территориях возводят фамильные церкви. Так, например, в усадебных дворянских церквях, расположенных вблизи господского дома или на территории усадьбы важное место занимала фамильная усыпальница. Только в крупных усадьбах сельский храм мог ограничиться размещением на территории фамильных некрополей и захоронений священнослужителей, а кладбище располагалось вблизи поселения, но не в пределах территории храма. Это было особенностью фамильных усадебных храмов - размещать только семейный некрополь. В качестве примера рассмотрим планировочную структуру русской усадьбы Нероново Солигаличского уезда Костромской губернии (рис. 4) [19]. На территории крупнейшей усадьбы располагался храм с фамильным некрополем. Анализ планировки показывает, что храм занимает одну из доминирующих позиций в структуре усадьбы, располагаясь на пересечении главной оси парадной линии застройки и парковой оси с водным партером. На территории фамильной церкви располагается семейная усыпальница.

Небольшие сельские храмы, как правило, включали кладбища, расположенные вблизи храма и эта территория была неотъемлемой функциональной частью сельского прихода. В настоящее время, при строительстве новых сельских храмов вопрос о размещении кладбища на территории храма не строит. Однако, сохранившиеся сельские храмы, исторические объекты нередко включают захоронения и территорию с кладбищем. Поэтому возникает целый ряд вопросов, связанных с организацией мест захоронений при современном благоустройстве территорий сельских храмов. Прежде всего, следует понимать, что при расчистке территорий разрушенных, руинированных храмов, могут встретиться сохранившиеся надгробия, или надгробия, перенесенные с места 
захоронения. В таком случае надгробие также может представлять ценность и являться неотъемлемой частью территории с захоронениями. Безусловно, некрополи - это отдельная тема, имеются ввиду только исторические надгробия, которые могут представлять информационную и художественную ценность. Следовательно, необходимо предусмотреть отдельную зону, где могут быть представлены сохранившиеся надгробия. Важно понимать, что память о местах захоронения, не должна нарушаться, и вопрос по преобразованию таких территорий является важным в современной организации исторических территорий храмовых комплексов.

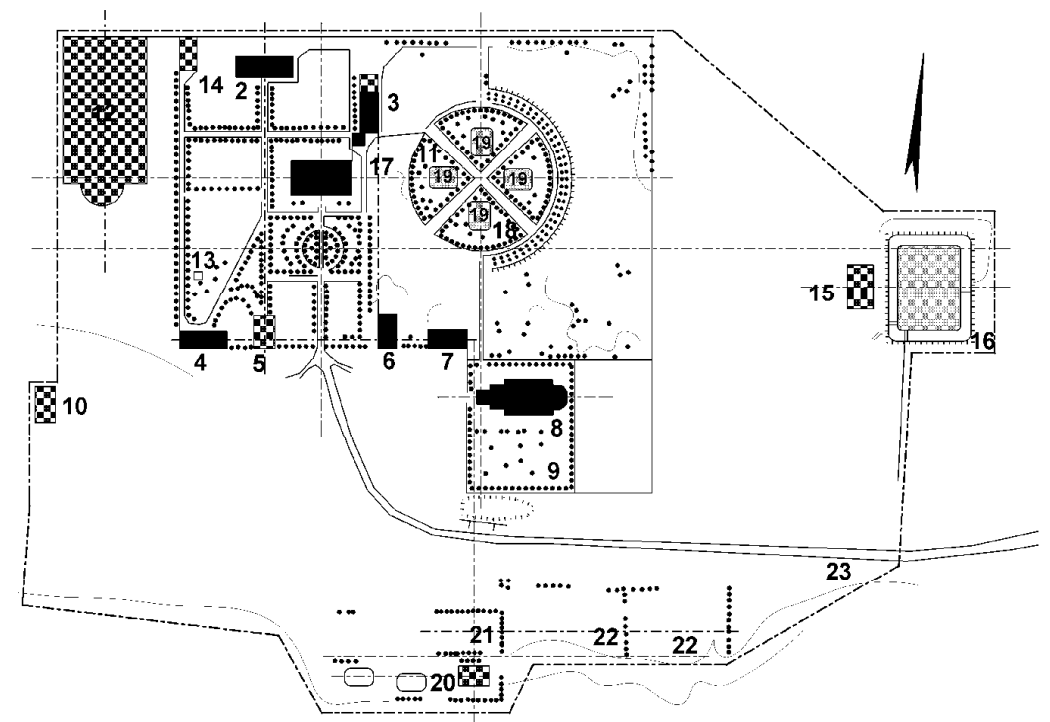

Рис. 4. Усадьба Нероново (Россия). Генплан: 1 - главный дом; 2 - дом управляющего

3 - хозяйственный флигель; 4 - дом помощника управляющего; 5 - амбар; 6 - баня;

7 - сторожка; 8 - церковь Воскресения; 9 - некрополь; 10 - дом священника; 11 - место паркового павильона; 12 - скотный двор; 13 - колодец; 14 - каретный сарай; 15 - прачечная; 16 - большой пруд; 17 - плодовый сад; 18 - «водный партер»; 19 - пруды; 20 - место грунтового сарая; 21 - место оранжереи и ягодного сада; 22 - хозяйственный двор; 23 - подъездная дорога

\section{5. Заключение}

Таким образом, представленные в настоящей статье предложения по функциональному зонированию архитектурного благоустройства территорий храмов с учетом исторической организации культовой территории, по комплектации элементов архитектурного благоустройства для наполнения функциональных зон и подзон, а также описанные особенности организации мест исторических захоронений близ храмов и благоустройства культовых мест, расположенных на территориях бывших дворянских усадеб в совокупности с необходимым финансированием позволят повысить качество осуществляемых проектных работ при проектировании генеральных планов территорий храмов и, соответственно, улучшить архитектурную среду рассматриваемых прихрамовых территорий.

\section{Литература}

[1] Drugamilau R., Chalavek i ruiny (natatki z padarozhzhau pa Magilyoy̆skaj voblasci), R. Drugamilau, Arhitektura i stroitel'stvo, 2009, № 6, s. 80-82.

[2] Zbor pomnikau gistoryi i kul'tury Belarusi. Bresckaya voblasc', Redkal.: S.V. Marceleu [i insh.], Minsk, 1984.

[3] Zbor pomnikau gistoryi i kul'tury Belarusi. Vicebskaya voblasc', Redkal.: S.V. Marceleu [i insh.], Minsk, 1985.

[4] Zbor pomnikau gistoryi i kul'tury Belarusi. Gomel'skaya voblasc', Redkal.: S.V. Marceleu [i insh.], Minsk, 1985. 
[5] Zbor pomnikau gistoryi i kul'tury Belarusi. Grodzenskaya voblasc', Redkal.: S.V. Marceleu [i insh.], Minsk, 1986.

[6] Zbor pomnikau gistoryi i kul'tury Belarusi. Minskaya voblasc'. Kniga 1, Redkal.: S.V. Marceleu [i insh.], Minsk, 1987.

[7] Zbor pomnikau gistoryi i kul'tury Belarusi. Minskaya voblasc'. Kniga 2, Redkal.: S.V. Marceleu [i insh.], Minsk, 1987.

[8] Zbor pomnikau gistoryi i kul'tury Belarusi. Magiley̆skaya voblasc', Redkal.: S.V. Marceleu [i insh.], Minsk, 1986.

[9] Globus Belarusi [Elektronnyj resurs], http://www.globus.tut.by/ (15.11.2020).

[10] Pravoslavnaya arhitektura Belarusi [Elektronnyj resurs], https://hram.by/ (15.11.2020).

[11] Arabej V.G., Farmiravanne arhitektury suchasnyh pryhodskih hramau Belaruskaj Pravaslay̆naj Carkvy: dys. ... kand. arhitektury, V.G. Arabej, Minsk, 2018.

[12] Kul'tovye zdaniya i sooruzheniya. Zdaniya, sooruzheniya i kompleksy pravoslavnyh hramov. Pravila proektirovaniya: TKP 45-3.02-83-2007 (02250), vved. 01.04.08, Minsk, 2008

[13] Svod pravil. Hramy pravoslavnye. Pravila proektirovaniya: SP 391.1325800.2017, vved. 23.06.18, M, 2018.

[14] Borisov S.V., Principy proektirovaniya pravoslavnogo hrama na osnove sistemy ob"emno-planirovochnyh elementov, S.V. Borisov, Arhitektura i sovremennye informacionnye tekhnologii [Elektronnyj resurs], 2011, № 3, https://marhi.ru/AMIT/2011/3kvart11/borisov/borisov.pdf (27.01.2021).

[15] Lipuga R.N., Arhitekturno-planirovochnaya organizaciya pravoslavnyh hramov yugo-vostochnoj Ukrainy s uchetom ih istoricheskogo razvitiya: dis. ... kand. arhitektury / R. N. Lipuga, Makeevka, 2015.

[16] Ukrainceva A.V., Issledovanie metodov ocenki proektnyh reshenij v arhitekture sovremennyh pravoslavnyh hramov Rossii, A.V. Ukrainceva, Arhitekton: izvestiya vuzov [Elektronnyj resurs], 2020, № 3, http:// archvuz.ru/2020_3/3/ (27.01.2021).

[17] Role of Natural Landscape in Perception of Ukrainian Sacral Architecture Monuments, D. Chernyshev, Y. Ivashko, D. Kuśnierz-Krupa, A. Dmytrenko, Landscape Architecture and Art, Jelgava, 2020, Vol. 6, p. 13-21.

[18] Drugomilov R.A., Blagoustrojstvo sel'skih poselenij (na primere Mogilevskoj oblasti): dis. ... kand. Arhitektury, R.A. Drugomilov, Minsk, 2011.

[19] Pamyatniki arhitektury Kostromskoj oblasti. Vyp. 4: Gorod Soligalich, Soligalichskij rajon, V.M. Rudchenko [i dr.], Kostroma, 2002.

\section{Functional organization of architectural improvement of the territories of rural parish churches}

ABSTRACT:

The article presents the suggestions for the functional zoning of the architectural improvement of the territories of churches, dividing into two main zones: public and service, which, in turn, are proposed to be divided into more compact subzones. A specific set of elements of architectural improvement is also proposed to fill the functional zones and subzones. The specifics of the organization of places of historical burial places near churches and the specifics of the architectural improvement of places of worship located on the territories of former noble estates are also described.

\section{KEYWORDS}

architectural improvement of the territories; churche, functional zoning 